\title{
BMJ Open Population characteristics, mechanisms of primary care and premature mortality in England: a cross-sectional study
}

\author{
Richard Baker, ${ }^{1}$ Kate Honeyford, ${ }^{1}$ Louis S Levene, ${ }^{1}$ Arch G Mainous III, ${ }^{2,3}$
} David R Jones, ${ }^{1}$ M John Bankart, ${ }^{4}$ Tim Stokes ${ }^{5}$

To cite: Baker $\mathrm{R}$

Honeyford K, Levene LS, et al. Population characteristics, mechanisms of primary care and premature mortality in England: a cross-sectional study. BMJ Open 2016;6: e009981. doi:10.1136/ bmjopen-2015-009981

\section{- Prepublication history and additional material is available. To view please visit the journal (http://dx.doi.org/ 10.1136/bmjopen-2015- 009981).}

Received 13 September 2015 Revised 2 December 2015 Accepted 31 December 2015

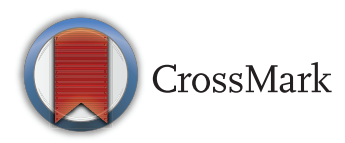

\footnotetext{
${ }^{1}$ Department of Health Sciences, University of Leicester, Leicester, UK ${ }^{2}$ Department of Health Services Research,

Management and Policy, University of Florida, Gainesville, Florida, USA ${ }^{3}$ Department of Community Health and Family Medicine, University of Florida, Gainesville, Florida, USA

${ }^{4}$ Department of Primary Care and Health Sciences,

University of Keele, Keele, UK

${ }^{5}$ Department of General

Practice and Rural Health, Dunedin School of Medicine, University of Otago, Dunedin, New Zealand
}

Correspondence to Professor Richard Baker; rb14@le.ac.uk

\section{ABSTRACT}

Objectives: Health systems with strong primary care tend to have better population outcomes, but in many countries demand for care is growing. We sought to identify mechanisms of primary care that influence premature mortality.

Design: We developed a conceptual model of the mechanisms by which primary care influences premature mortality, and undertook a cross-sectional study in which population and primary care variables reflecting the model were used to explain variations in mortality of those aged under 75 years. The premature standardised mortality ratios (SMRs) for each practice, available from the Department of Health, had been calculated from numbers of deaths in the 5 years from 2006 to 2010. A regression model was undertaken with explanatory variables for the year 2009/2010, and repeated to check stability using data for $2008 / 2009$ and 2010/2011.

Setting: All general practices in England were eligible for inclusion and, of the total of 8290 , complete data were available for 7858 .

Results: Population variables, particularly deprivation, were the most powerful predictors of premature mortality, but the mechanisms of primary care depicted in our model also affected mortality. The number of GPS/1000 population and detection of hypertension were negatively associated with mortality. In less deprived practices, continuity of care was also negatively associated with mortality.

Conclusions: Greater supply of primary care is associated with lower premature mortality even in a health system that has strong primary care (England). Health systems need to sustain the capacity of primary care to deliver effective care, and should assist primary care providers in identifying and meeting the needs of socioeconomically deprived groups.

\section{INTRODUCTION}

Health systems in many countries face financial constraints, but at the same time, they are also experiencing increased demand because of population ageing and, in some countries, population growth. Health systems

\section{Strengths and limitations of this study}

- The study included all general practices in England for which the necessary data were available (7858 practices included out of a total of 8290).

- A conceptual model, informed by previous research evidence, was developed prior to the analysis, to guide the selection of explanatory variables hypothesised to affect premature mortality. The model highlighted the potential roles of (1) the capacity of primary care, (2) access to care (including continuity), (3) clinical care (prevention, detection and management of disease) and (4) the performance of consultations in affecting premature mortality.

- The study was cross-sectional, and this limits the ability to draw conclusions about causality. A longitudinal study was not possible because the necessary data were not available.

- The study used standardised mortality ratios as the measure of mortality. The use of count data would have been preferable, but these data were not available.

- The regression model explained a high proportion of the variation in premature mortality. We checked the stability of the regression model by using data for explanatory variables for three different years.

with stronger primary care, such as those in England, tend to achieve better health outcomes while restricting costs. ${ }^{1}{ }^{2}$ However, the mechanisms by which primary care influences outcomes such as mortality are only partly understood, although health system configuration, supply of physicians and continuity of care appear important. ${ }^{3}$ The introduction of a country-wide primary care strategy in Brazil was followed by a decline in cardiovascular mortality ${ }^{4}$; in the USA, supply of primary care physicians has been associated with reduced population mortality; ${ }^{5}$ and in England, relational continuity in primary care has been associated with lower mortality. ${ }^{6}$ 
Starfield postulated six mechanisms by which primary care can affect population health: (1) greater access to services, (2) better quality of care, (3) greater focus on prevention, (4) early clinical management, (5) the effect of primary care characteristics (focus on the person, continuity) and (6) reduction of unnecessary specialist care. ${ }^{3}$ Primary care interventions may affect various outcomes and, in this paper, we focus on mortality. The characteristics of patients, including age, lifestyles and morbidity, have important effects on premature mortality. In particular, socioeconomic deprivation is a powerful predictor of mortality. However, primary care is expected to incorporate a population health perspective that includes responding to the health needs of deprived groups, ${ }^{7}$ and a key objective for primary care set by the WHO is to contribute to health equity and social justice. ${ }^{8}$

Our aim was to investigate whether a conceptual model representing some of the proposed mechanisms of primary care explains variations in premature mortality in general practice populations, taking particular account of deprivation among population characteristics. We hypothesised that the capacity of primary care (supply of general practitioners and their efficiency), access to care (being able to get an appointment with a general practitioner and relational continuity with a general practitioner) and the delivery of effective clinical care (prevention, detection and management of disease, and performance in consultations), would influence premature mortality.

\section{METHOD}

\section{Study design}

We undertook a cross-sectional study, in England, of premature mortality rates of patients of general practices (the main providers of English primary care) to identify variations in general practice associated with variations in mortality, while accounting for population characteristics. Since general practices have small populations, wide variations in mortality rates can occur from year to year. ${ }^{9}$ Therefore, published data over a 5 -year period, provided by the Department of Health to the Health and Social Care Information Centre, ${ }^{10}$ were used to provide more stable mortality rates at practice level. We used data on population and practice characteristics for the year 2009-2010 as explanatory variables, and repeated the analysis with data from 2008/2009 and $2010 / 2011 .{ }^{10}$ All data were publicly available and, therefore, ethics committee approval was not required.

\section{Study sample}

All practices for which mortality data were published were eligible for inclusion $(n=8290)$.

\section{Mortality}

We used the standardised mortality ratio (SMR) of those under the age of 75 years as the measure of premature mortality. ${ }^{11}$ The Office of National Statistics in England has recommended defining premature mortality as death under the age of 75 years. ${ }^{12}$ The SMR is the ratio of the observed to expected number of deaths, the expected number of deaths being calculated using agespecific death rates for England and applied to local areas, determined by the Office of National Statistics, known as middle-level super output areas (MSOAs). ${ }^{13}$ MSOAs have an average population of 5000, allowing reliable estimates of mortality rates to be calculated. The number of observed deaths had been calculated at practice level by the government's Department of Health for the period 2006-2010 by taking a weighted average of the mortality data for each MSOA in which a given practice's patients live. The weights are the percentage of the practice's patients residing in each MSOA.

\section{Predictor selection}

To guide the selection of predictor variables and to summarise our hypotheses, we developed a conceptual model explaining how population characteristics and primary care mechanisms influence mortality (figure 1). The model drew on Starfield's mechanisms ${ }^{3}$ and a model we had devised previously. ${ }^{6}$ In the model, population characteristics are expected to have the major impact. The model postulates a mechanism in which capacity of primary care will influence access, and access will enable patients to obtain preventive care, detection of illnesses and disease management. Our conceptual model focuses on primary care, but it recognises that public health, as well as secondary and social care, also affect mortality, as does the degree of connectedness between sectors.

\section{Population predictors}

Demographic characteristics related to premature mortality ${ }^{614}$ were considered for inclusion. These included a measure of deprivation-the Index of Multiple Deprivation 2010 (IMD 2010)—which combines indicators in seven domains (income, employment, health, education, housing, crime and environment) into a score for each small area in England. ${ }^{15}$ The GP Practice IMD was estimated by taking a weighted average of the IMD scores for each lower-level super output area (LSOA) in which a given practice had registered patients. ${ }^{16}$ A LSOA has a population size of approximately 1500 people, and provides a more discriminating unit for calculation of practice population deprivation scores than use of the larger population unit of MSOAs. We included an estimate of smoking in those with chronic conditions, derived from pay for performance indicators for chronic disease management (the UK quality and outcomes framework for general practiceQOF) ${ }^{14}$ To reflect the underlying chronic disease morbidity of the practice population, we selected the prevalence of diabetes, based on QOF registers. General practice diabetes registers are good measures of the prevalence of diabetes, ${ }^{17}$ and, in a recent study from 
Figure 1 Model of how population and primary care characteristics are postulated to influence population mortality; characteristics of social and secondary care and public health not included. Modified from Levene et $a^{\rho}$ to include Starfield et als $\mathrm{s}^{3}$ mechanisms: ${ }^{1}$ greater access; ${ }^{2}$ better quality of care; ${ }^{3}$ greater focus on prevention; ${ }^{4}$ early management of health problems; ${ }^{5}$ primary care characteristics; ${ }^{6}$ reducing unnecessary specialist care.


National features - health system, economy, policies affecting health (e.g. food, road safety)
Scotland, $47 \%$ of people with diabetes were found to have at least three other chronic conditions. ${ }^{18}$ The percentage of the practice population who were white was taken from the GP patient survey. ${ }^{19}$ We undertook sensitivity analyses comparing the use of these data with estimates of the ethnicity of practice populations derived from hospital admissions for 2005-2007. ${ }^{20}$

\section{Primary care predictors}

We used numbers of full-time equivalent general practitioners (GPs)/1000 population, a measure designed by the National Health Service (NHS) Information Centre to describe the capacity of each practice in relation to the population served. ${ }^{21}$ The measure includes all GPs except those in training, and used a measure of the patient population weighted according to patient need. We used the total number of patients registered with the practice list as a measure of efficiency, ${ }^{22}$ since larger practices potentially have opportunities for efficiencies. ${ }^{23}$

Our model distinguished between capacity and access, ${ }^{24}$ for which we used patient reports collected through the annual GP patient survey, specifically the percentage of patients who recalled being able to make an appointment within $48 \mathrm{~h} .{ }^{19}$ Similarly, we used the percentage of patients who recalled being able to make an appointment with a GP in advance as a measure of continuity. The GP patient survey includes random samples of the adult population of every general practice, and these survey items were selected because they have been shown to be adequately reliable for allocating access incentive payments to practices. $^{25}$ We also included another survey measure expressing patients' trust and confidence in their GP as a measure of consultation performance.

Indicators from the QOF were adopted as measures of prevention, detection and management. We used a study of the estimated public health impact of QOF indicators to select the prevention and management indicators with the greatest potential impact on mortality, ${ }^{26}$ while at the same time limiting the number of indicators, to reduce the risk of identifying spurious associations. For prevention, we used the percentage of patients with diabetes having influenza immunisation (estimated annual mortality reduction 63.7/100000 patients ${ }^{26}$ ), and the proportion of smokers with a chronic condition who were offered help with cessation (estimated annual mortality reduction 10.9/100 $000^{26}$ ). For detection, we used the proportion of patients recorded as having atrial fibrillation with the diagnosis confirmed by an ECG or specialist, and the proportion of patients on the practice hypertension register, since greater detection of hypertension is associated with lower coronary heart disease and stroke mortality rates. ${ }^{6}$

For management, underlying achievement of selected QOF indicators was used, that is, the percentage of eligible patients for whom a target has been achieved. We used the percentage of patients with hypertension in whom the last blood pressure reading was 150/ $90 \mathrm{~mm} \mathrm{Hg}$ or less (estimated annual mortality reduction $48.2 / 100000^{26}$ ), the percentage of patients with coronary heart disease currently treated with a $\beta$-blocker (estimated annual mortality reduction $45.9 / 100000^{26}$ ), the percentage of patients with diabetes in whom the last glycated haemoglobin (HbA1c) level was $7.0 \%$ 
$(53.0 \mathrm{mmol} / \mathrm{mol}$ ) or less (estimated annual mortality reduction $26.5 / 100000^{26}$ ), and the percentage of patients on the chronic kidney disease register in whom the last blood pressure reading was $140 / 85 \mathrm{~mm} \mathrm{Hg}$ or less (estimated annual mortality reduction 26.2/ $\left.100000^{26}\right)$.

\section{Statistical analysis}

The analysis sought to determine the potential effect of all candidate explanatory variables on indirectly standardised premature mortality rates, calculated from deaths in 2006-2010. QOF and patient survey data from 2009/ 2010 were used as explanatory variables in the primary analysis. Stata V.11 was used to undertake the analysis (StataCorp. Stata data analysis and statistical software. Release 11. New in Stata 11. http://www.stata.com/ stata11/ (accessed 8 Apr 2015)). No formal adjustment for multiple hypothesis testing (multiplicity) was made.

In stage 1 , we undertook univariable analysis of all explanatory variables. In stage 2 , we developed a multiple linear regression model of premature SMR including all explanatory variables without transformation, to assess our conceptual model. The errors were assumed to follow a normal distribution, with regression diagnostics supporting this assumption. Counts of deaths were not available, and it was not possible to use a count model. ${ }^{27}$ Primary care trusts and mortality estimates, based on local areas that overlap for some general practices, cannot be considered independent. We adjusted for the clustering effect by using robust SEs. ${ }^{28}$

To test the stability of the regression model, we repeated it using QOF and patient survey variables from 2008/2009 and 2010/2011. Data from 2007/2008 and earlier were not used as there were changes to the patient survey in 2008/2009. As the distribution of premature SMR was positively skewed, the $\log$ of the SMR was also modelled.

Stage 3 sought to determine the possible interactions between deprivation and primary care characteristics. Interactions between primary care characteristics and deprivation were then examined in the model, one at a time. Aikaike and Bayesian Information Criteria (AIC and $\mathrm{BIC})^{29}$ were used to determine whether including an interaction improved model fit.

\section{RESULTS}

There were 8290 general practices in England in 2009/ 2010. Of these, 432 were omitted from the analysis for the following reasons: missing data on deprivation of the practice population $(n=63)$; missing data on ethnicity of the practice population $(n=153)$; missing data for QOF indicators $(n=29)$; missing data on exception reporting of QOF indicators $(n=9)$; missing data on numbers of GPs/1000 ( $n=105)$; incomplete general practice patient survey data $(n=15)$; practices with no patients to whom QOF indicators applied $(n=58)$. The final number of practices included was 7858 .
The median premature SMR was 103 (IQR: 85 to 125), ranging from 34 to 223. Univariable analysis of individual explanatory variables indicated that increasing deprivation, smoking and diabetes prevalence were positively associated, and white ethnicity negatively associated, with premature mortality (table 1). All aspects of patient experience were negatively associated with premature mortality, although the proportion of the variation explained was low. Hypertension detection was negatively associated with premature mortality, but a mixed pattern was found when the other clinical management variables were considered.

The regression model (table 2) explained $84 \%$ of the variation in premature mortality. Of the population characteristics, increasing deprivation, increasing proportions of the practice population who were white, increasing proportions with diabetes and increasing proportions who were smokers, were associated with higher mortality.

Of the practice predictors, increasing numbers of GPs/1000 population (capacity), increasing proportions able to get an appointment within $48 \mathrm{~h}$ (access), increasing numbers of patients on hypertension registers (detection) and increasing proportions of those with hypertension with blood pressure below 150/90 $\mathrm{mm} \mathrm{Hg}$ (management), were all associated with lower mortality. Increasing proportions of those with coronary heart disease treated with a $\beta$-blocker, increasing proportions of patients with diabetes in whom the last HbAlc level was $7.0 \%$ or less and increased proportions of patients with chronic kidney disease with blood pressure below 140/85 mm Hg were all associated with increasing SMR, although the coefficients for all the management (and some other) variables were very small.

Based on this model, the benefits from primary care may be quite small at the level of a practice, but would be much greater when aggregated to all of England (table 3). Using MSOA level data on the numbers of deaths in small populations, we have estimated that a practice with a median list size of 6009 patients (see table 1) could be expected to have 20 deaths in 1 year, based on an SMR of between 95 and 105. An increase in hypertension detection of $1 \%$ was associated with an annual reduction of 0.16 premature deaths, but when aggregated to the whole of England, this equates to a potential decrease of 1202 premature deaths. This approach was used to calculate the possible impact on the number of premature deaths in England of a one unit change in each explanatory variable, shown in table 3. In 2009/2010, the median number of patients per GP was 1800; decreasing this to 1400 (equivalent to an additional 8500 full time GPs in post) would equate to 0.14 fewer premature deaths annually in a practice, and 1078 in England as a whole.

In stage 3 of the analysis, interactions between deprivation and five service characteristics improved the model fit. There were negative interactions between deprivation and GP supply, the proportion of patients able to make 
Table 1 Explanatory variables (2009/2010) for practices in England $(n=7858)$

\section{Variable}

Median (IQR)

(Minimum,

Univariable $\beta$-coefficient

Population characteristics

IMD 2010

(95\% Cl)

p Value $R^{2}$

Proportion of the practice population who are white (\%)

$21.55(13.57,31.85)$

$(2.86,66.30)$

2.00 (1.98 to 2.02)

$<0.001$

$-0.335(-0.362$ to -0.309$)$

$<0.001 \quad 0.074$

Proportion of those with chronic conditions who are smokers (\%)

$91.60(77.14,95.24)$

$(0.56,100.00)$

$2.86(2.80$ to

$<0.001$

$5.37(4.59,6.23)$

$(0.33,14.77)$

6.14 (5.78 to 6.50$)$

$<0.001 \quad 0.12$

register (\%)

Efficiency

Registered list size

Supply

Number of GPs per 1000 patients

Access

Proportion of patients reporting being able to get an appointment within $48 \mathrm{~h}(\%)$

Continuity of care and quality of relationship

Proportion of patients reporting being able to get an appointment in advance (\%)

Proportion of patients expressing trust in their GP (\%)

Prevention

DM18 The percentage of patients with diabetes who have had influenza immunisation in the preceding 1 September to 31 March (\%)

SM04 The percentage of patients with any or any combination of 10 specified conditions who smoke, and whose notes contain a record that

moking cessation advice or referral to a specialist service, where available,

has been offered within the previous 15 months

Detection

AF04 The percentage of patients with atrial fibrillation diagnosed after 1 April 2008 with ECG or specialist-confirmed diagnosis

Proportion of practice population on the QOF hypertension register (\%)

Clinical management

BP05 The percentage of patients with hypertension in whom the last blood pressure (measured in the previous 9 months) is 150/90 or less

CHD10 The percentage of patients with coronary heart disease who are currently treated with a $\beta$-blocker (unless a contraindication or side effects are recorded)

DM23 The percentage of patients with diabetes in whom the last $\mathrm{HbA1c}$ level is 7 or less (or equivalent test/reference range depending on local laboratory) in the previous 15 months

CKD03 The percentage of patients on the CKD register in whom the last blood pressure reading, measured in the previous 15 months, is $140 / 85$ or less

$\mathrm{AF}$, atrial fibrillation; $\mathrm{BP}$, blood pressure; $\mathrm{CHD}$, coronary heart disease; CKD, chronic kidney disease; DM, dia
$\mathrm{IMD}$, Index of Multiple Deprivation; QOF, quality and outcomes framework; SMR, standardised mortality ratios.
$6009(3557,9290)$

$0.557(0.460,0.668)$

$83.33(75.00,90.07)$

$73.89(62.13,84.02)$

$95.42(92.82,97.05)$

$78.39(74.28,82.31)$

$92.43(90.31,95.15)$

$(406,39919) \quad-0.0012(-0.0013$ to -0.0010$)<0.001 \quad 0.034$

$(0.000,5.837)$

$-7.08(-9.66$ to -4.50$)$

$<0.001$

0.004

(22.01, 100)

$-0.59(-0.64$ to -0.54$)$

$<0.001$

0.061

$(14.81,100)$

$-0.34(-0.38$ to -0.30$)$

$<0.001$

0.037

$(66.67,100)$

$-2.02(-2.17$ to -1.88$)$

$<0.001$

0.088

$(25.00,100)$

$-0.41(-0.50$ to -0.32$)$

$<0.001$

0.010

(33.60, 100)

$-0.15(-0.27$ to -0.038$)$

0.009

0.0009

$91.30(85.11,100.00)$

$(0.00,100)$

$0.018(-0.031$ to 0.066$)$

0.471

0.0001

$13.55(11.48,15.68)$

$(0.16,36.65)$

$-1.18(-1.35$ to -1.01$)$

$<0.001$

0.024

$76.16(71.82,80.31)$

(38.30, 99.45)

$-0.22(-0.31$ to -0.13$)$

$<0.001$

0.003

$56.39(51.62,61.14)$

(16.33, 100)

$0.25(0.18$ to 0.33$)$

$<0.001$

0.005

$46.58(41.00,52.44) \quad(0,96.40)$

$-0.22(-0.29$ to -0.16$)$

$<0.001$

0.006

$69.20(63.50,75.00) \quad(0.00,100)$

$0.22(0.16$ to 0.28$)$

$<0.001$

0.006 
Table 2 Multiple linear regression results for under 75 years SMR for practices in England $(n=7856)$

\begin{tabular}{|c|c|c|c|}
\hline Variable & $\beta$-Coefficient & $95 \% \mathrm{Cl}$ & p Value \\
\hline \multicolumn{4}{|l|}{ Population characteristics } \\
\hline IMD 2010 & 1.81 & (1.69 to 1.94$)$ & $<0.001$ \\
\hline Proportion of the practice population who are white (\%) & 0.17 & (0.10 to 0.25$)$ & $<0.001$ \\
\hline Proportion of those with chronic conditions who are smokers (\%) & 0.49 & (0.39 to 0.64$)$ & $<0.001$ \\
\hline $\begin{array}{l}\text { Proportion of the practice population who are on the practice's diabetes } \\
\text { register (\%) }\end{array}$ & 1.30 & $(0.50$ to 2.11$)$ & 0.002 \\
\hline \multicolumn{4}{|l|}{ Efficiency } \\
\hline Registered list size & 0.00002 & $(-0.00008$ to 0.0001$)$ & 0.739 \\
\hline \multicolumn{4}{|l|}{ Supply } \\
\hline Number of GPs per 1000 patients & -4.31 & $(-6.80$ to -1.82$)$ & $<0.001$ \\
\hline \multicolumn{4}{|l|}{ Access } \\
\hline $\begin{array}{l}\text { Proportion of patients reporting being able to get an appointment within } \\
48 \mathrm{~h}(\%)\end{array}$ & -0.06 & $(-0.11$ to -0.02$)$ & 0.006 \\
\hline \multicolumn{4}{|l|}{ Continuity of care and quality of relationship } \\
\hline $\begin{array}{l}\text { Proportion of patients reporting being able to get an appointment in } \\
\text { advance (\%) }\end{array}$ & -0.01 & $(-0.04$ to 0.01$)$ & 0.283 \\
\hline Proportion of patients expressing trust in their GP (\%) & 0.03 & $(-0.10$ to 0.16$)$ & 0.635 \\
\hline \multicolumn{4}{|l|}{ Prevention } \\
\hline $\begin{array}{l}\text { DM18 The percentage of patients with diabetes who have had influenza } \\
\text { immunisation in the preceding } 1 \text { September to } 31 \text { March (\%) }\end{array}$ & 0.007 & $(-0.06$ to 0.08$)$ & 0.849 \\
\hline $\begin{array}{l}\text { SM04 The percentage of patients with any or any combination of } 10 \\
\text { specified conditions who smoke, and whose notes contain a record that } \\
\text { smoking cessation advice or referral to a specialist service, where } \\
\text { available, has been offered within the previous } 15 \text { months }\end{array}$ & -0.02 & $(-0.08$ to 0.04$)$ & 0.587 \\
\hline \multicolumn{4}{|l|}{ Detection } \\
\hline $\begin{array}{l}\text { AF04 The percentage of patients with atrial fibrillation diagnosed after } 1 \\
\text { April } 2008 \text { with ECG or specialist confirmed diagnosis }\end{array}$ & -0.002 & $(-0.032$ to 0.029$)$ & 0.918 \\
\hline Proportion of practice population on the QOF hypertension register (\%) & -0.77 & $(-0.98$ to -0.56$)$ & $<0.001$ \\
\hline \multicolumn{4}{|l|}{ Clinical management } \\
\hline $\begin{array}{l}\text { BP05 The percentage of patients with hypertension in whom the last } \\
\text { blood pressure (measured in the previous nine months) is } 150 / 90 \text { or less }\end{array}$ & -0.077 & $(-0.15$ to -0.004$)$ & 0.04 \\
\hline $\begin{array}{l}\text { CHD10 The percentage of patients with coronary heart disease who are } \\
\text { currently treated with a } \beta \text {-blocker (unless a contraindication or side effects } \\
\text { are recorded) }\end{array}$ & 0.088 & (0.018 to 0.16$)$ & 0.015 \\
\hline $\begin{array}{l}\text { DM23 The percentage of patients with diabetes in whom the last } \mathrm{HbA} 1 \mathrm{c} \\
\text { level is } 7 \text { or less (or equivalent test/reference range depending on local } \\
\text { laboratory) in the previous } 15 \text { months }\end{array}$ & 0.06 & $(-0.003$ to 0.13$)$ & 0.061 \\
\hline $\begin{array}{l}\text { CKD03 The percentage of patients on the CKD register in whom the last } \\
\text { blood pressure reading, measured in the previous } 15 \text { months, is } 140 / 85 \\
\text { or less }\end{array}$ & 0.0390 & $(-0.0097$ to 0.0877$)$ & 0.116 \\
\hline
\end{tabular}

Statistical model: multiple linear regression of premature SMR with robust errors to account for clustering. No formal adjustment for multiplicity. CKD, chronic kidney disease; DM, diabetes mellitus; GPs, general practitioners; HbA1c, glycated haemoglobin; SMR, standardised mortality ratios.

an appointment within $48 \mathrm{~h}$ or in advance and those expressing trust in their GP. A positive interaction was found between deprivation and the percentage of patients on the coronary heart disease (CHD) register treated with $\beta$-blocker. The inclusion of the interaction term for each of the five service characteristics suggests that the impact of an improvement in supply, access, continuity of care and consultation quality is lower for practices serving a more deprived community. The percentage of patients with CHD treated with a $\beta$-blocker was positively associated with mortality, again inclusion of the interaction term reduced the impact of an improvement in management in patients serving more deprived patients. This is illustrated in table 4 .

\section{Sensitivity analysis}

The findings of analyses of the 3 years separately (2008/ 2009, 2009/2010, 2010/2011) gave consistent conclusions with only minor differences. More details are given in the online supplementary appendix. The results of the $\log$ transformed model were also consistent with the original model, although the fit of the logged model may be inferior. When practice size was modelled as a categorical variable, to indicate the smallest $10 \%$ of practices, there was evidence that practice size was associated with premature mortality. Small practices, with a list size of 2367 (identifying the smallest $10 \%$ of practices), were associated with higher premature mortality. 
Table 3 Impact of a 1 unit $^{*}$ change in explanatory variables in terms of the numbers of premature deaths in England, given the other variables in the model

\section{Potential reduction in premature deaths in England in 1 year if there is a 1 unit $^{*}$ change in the explanatory variable $(95 \% \mathrm{Cl}) \dagger$}

\section{Population characteristics}

Change is a decrease in 1 unit that is associated with a reduction in deaths for all variables

Reduction in IMD of 1 unit

Reduction of $1 \%$ in the proportion of the practice population who are white

Reduction of $1 \%$ in the proportion of those with chronic conditions who are smokers

2830 (2642 to 3033$)$

269 (156 to 391$)$

764 (610 to 1001$)$

2032 (782 to 3299$)$

diabetes register

Primary care characteristics

Change is an increase in 1 unit that is associated with a reduction in deaths for some variables and an increase in deaths for others

Efficiency

Increase in 1000 patients in registered list size ${ }^{\star}$

$-25(-156$ to 81$)$

Supply

Increase of $1.00 \mathrm{GPs}$ per 1000 patients

Increase of 0.16 GPs per 1000 patients*

6738 (2845 to 10631$)$

1078 (455 to 1701 )

Access

Increase of $1 \%$ in the proportion of patients reporting being able to get an appointment

within $48 \mathrm{~h}$

Continuity of care and quality of relationship

Increase of $1 \%$ in the proportion of patients reporting being able to get an appointment in advance

Increase of $1 \%$ in the proportion of patients expressing trust in their GP

Prevention

Increase of $1 \%$ in the percentage of patients with diabetes who have had influenza

immunisation in the preceding 1 September to 31 March (DM18)

Increase of $1 \%$ in the percentage of patients with any or any combination of 10 specified

conditions who smoke, and whose notes contain a record that smoking cessation advice

96 (31 to 172$)$ or referral to a specialist service, where available, has been offered within the previous 15 months (SM04)

Detection

Increase of $1 \%$ in the percentage of patients with atrial fibrillation diagnosed after 1 April 2008 with ECG or specialist-confirmed diagnosis (AF04)

Increase of $1 \%$ in the proportion of practice population on the QOF hypertension register

Clinical management

Increase of $1 \%$ in the percentage of patients with hypertension in whom the last blood pressure (measured in the previous 9 months) is $150 / 90$ or less (BP05) Increase of $1 \%$ in the percentage of patients with coronary heart disease who are currently treated with a $\beta$-blocker (unless a contraindication or side effects are recorded) (CHD10)

Increase of $1 \%$ in the percentage of patients with diabetes in whom the last $\mathrm{HbA1c}$ level is

7 or less (or equivalent test/reference range depending on local laboratory) in the previous 15 months (DM23)

Increase of $1 \%$ in the percentage of patients on the CKD register in whom the last blood pressure reading, measured in the previous 15 months, is 140/85 or less (CKD03)

$$
\begin{aligned}
& 21(-16 \text { to } 63) \\
& -49(-250 \text { to } 156) \\
& -10(-125 \text { to } 63) \\
& 25(-63 \text { to } 125)
\end{aligned}
$$

$$
2(-45 \text { to } 50)
$$

1202 (875 to 1532$)$

$$
121 \text { (6 to 234) }
$$$$
-137(-250 \text { to }-28)
$$

$$
-100(-203 \text { to } 5)
$$

*All variables are a one unit change apart from GPs per 1000 patients and list size where changes that are more applicable to practices have been chosen. A change in GPs/1000 of 0.16 is equivalent to a reduction in list size from 1800 to 1400 .

†Negative figures indicate a negative reduction in deaths, that is, an increase in deaths.

CKD, chronic kidney disease; DM, diabetes mellitus; GPs, general practitioners; HbA1c, glycated haemoglobin; IMD, Index of Multiple Deprivation; SMR, standardised mortality ratios.

\section{DISCUSSION}

Principal findings

Population variables were the most powerful predictors of mortality. Practices with greater levels of diabetes, more smokers, more white patients and greater deprivation, had higher levels of premature mortality. Deprivation had the greatest effect. Although non-white ethnicity was associated with higher premature mortality 


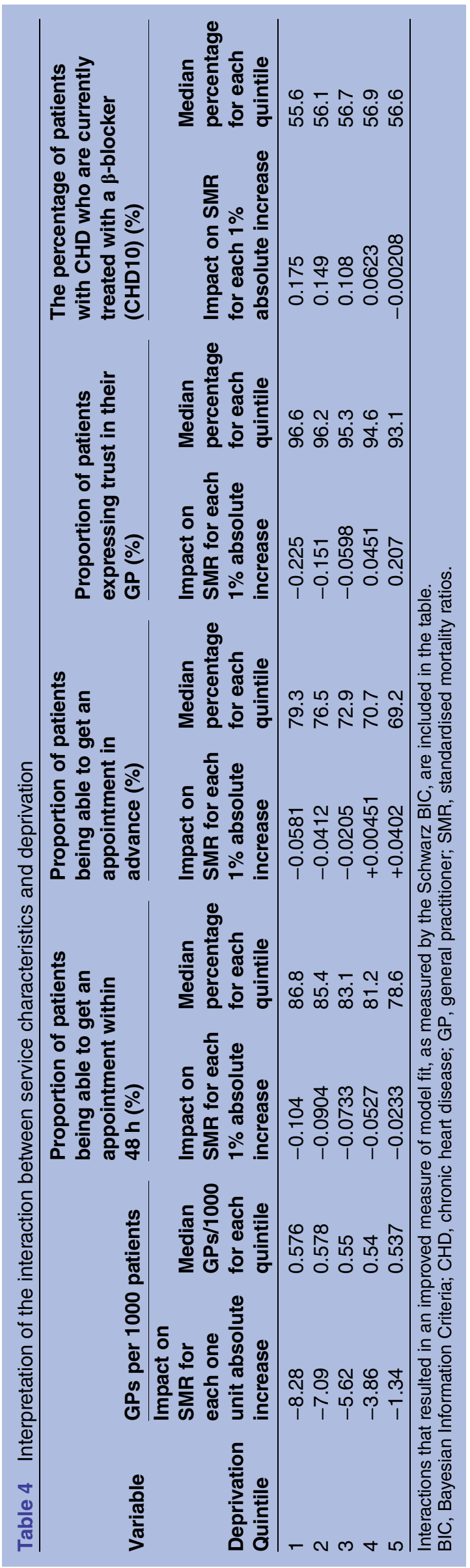

in the univariate analysis, once deprivation had been included in the multivariate analysis, higher proportions of white patients were associated with higher mortality, although the coefficient was small. This effect of adjustment for deprivation has been reported previously, ${ }^{30} 31$ and the finding may also be influenced by characteristics of the IMD and, possibly, inconsistencies in the recording of ethnicity. There is debate about the inclusion of measures of deprivation in assessments of clinical performance, ${ }^{32}$ but we included deprivation in our model in view of its importance in predicting mortality.

Characteristics of primary care indicative of the mechanisms in our model also predicted premature mortality, although less so than population characteristics. Greater numbers of GPs (capacity of primary care) were associated with lower premature mortality, as was access, although for access, the size of effect of access was negligible. This finding supports proposals to increase GP numbers, ${ }^{2}$ but data at practice level on numbers of primary care nurses and other staff were not available. An increase in the numbers of these staff might reduce the need for an increase in the numbers of GPs. Our measure of efficiency-practice size-did not predict mortality, although sensitivity analysis suggested that smaller practice size, when treated as a categorical variable, was associated with higher mortality. It is possible that greater efficiency does not improve care for those most in need, or that practice size was not a good measure of efficiency. ${ }^{22}{ }^{23}$ An alternative measure of efficiency, such as the experience of the practice manager or the number of nurse-led clinics provided by the practice, was not available, and therefore this finding should be viewed with caution. Neither variations in the measure of continuity nor those in the measure of consultation performance were associated with mortality, but when the effect was related to variations in deprivation, continuity was associated with lower mortality in less deprived practices. Other studies have identified an association between continuity and mortality. ${ }^{63}$ It is possible that the negative finding is due to the measures not adequately reflecting the concepts of continuity and consultation performance, but it may also be explained by the modifying effect of deprivation. Greater deprivation was also associated with the reduced effect of GP supply. Detection of hypertension did predict mortality, as found in other studies restricted to coronary heart disease and stroke. ${ }^{6}{ }^{34}$ The measures of clinical management had only small and inconsistent relationships to mortality, and were not stable over the 3 years investigated. A potential explanation is the only limited variability in performance between practices that the QOF has engendered. This finding accords with a recent UK study that demonstrated little impact of QOF on mortality. ${ }^{35}$ A further potential explanation is that an increase in volume may be associated with an improvement in quality of care, in which case the indicators may, to some extent, reflect prevalence. ${ }^{36}$ 


\section{Strengths and limitations}

This study included an entire country in a practice level analysis, with repetition of the regression model in 3 years to check its stability, and the use of a conceptual model to explain how the mechanisms of primary care influence outcomes. The mechanisms of the model were derived from review of available evidence, ${ }^{3}$ and the associations found in the regression analysis tend to support several of them. However, the study was crosssectional only, and it is important to recognise that definitive assumptions about causation cannot be made. Our conceptual model was focused on the role of primary care, but community and specialist secondary care, and public health services, also affect health outcomes. Practice level mortality is, therefore, a result of care by these other components of care plus population characteristics, in addition to the specific contribution of primary care.

The majority of data used for the explanatory variables were obtained from sources that have been used for administrative purposes and in research studies for several years, such as the quality and outcomes framework. The data collection systems are well established, and the advantages and disadvantages of these data have become well understood. Nevertheless, there were some potential limitations in the variables used. For example, the response rates to the general practice patient survey tend to be low, although there is evidence to support reliability, ${ }^{25}$ and alternative measures of access and continuity were not available. Recorded diabetes prevalence is not an ideal measure of the level of chronic disease morbidity in a population; unfortunately, the use of a composite measure derived from a quality and outcome framework smoking indicator was not possible since the measure included hypertension as one of the chronic conditions taken into account. The study used data from five or more years ago, although these data were the most recent available for practice level mortality. The mortality data related to the 2006-2010 period, although we used data on practice characteristics for 2009/2010. After the introduction of the QOF, performance improved during the first 2 or 3 years, but thereafter remained relatively stable, ${ }^{37} 38$ and therefore changes in practice performance are unlikely to have influenced our findings. The study used practice level data, and further research using patient level data would be desirable. Linear regression of age-adjusted rates when the explanatory variables are not age-adjusted can introduce bias. However, sensitivity analysis including age variables did not impact on the size of effect of deprivation as an explanatory variable or size of the effect. Although negative binomial regression of counts of deaths would be preferred, ${ }^{27}$ the data available meant that this approach was not possible.

\section{Implications and future research}

The population characteristics of deprivation and higher levels of morbidity predicted mortality, but the detection of hypertension and the capacity of primary care, measured in our study by the supply of GPs, also had effects. Although the effects of primary care were small at practice level, the implications for total annual numbers of deaths are important; the associations between detection of hypertension, and numbers of GPs and mortality, suggest that improvement in these aspects of primary care have potential to make worthwhile reductions in mortality. The finding on numbers of GPs supports the case that general practice in England lacks capacity to meet demand. Levels of detection of hypertension have been shown to be associated with the supply of GPs and patient access. ${ }^{39}$ An increase in the numbers of GPs is required, therefore, not only to improve the convenience of access but also to improve population health. If steps are taken to increase capacity, a longitudinal study of premature mortality should be undertaken to monitor the impact. Since international comparisons rate access in England highly, ${ }^{40}$ our finding is even more important to countries with health systems where access is more limited. Our findings on the role of deprivation, including the reduced impact of primary care mechanisms, indicate that special attention must be given to the needs of deprived populations. ${ }^{41}$ In addition to concentration of resources in practices that care for large numbers of deprived people, targeted public health and social care measures have a role to play. These might be facilitated by improving responsiveness to local population characteristics. ${ }^{42}$

Contributions RB and KH conceived the study. LSL, RB, AGM, TS and KH developed the conceptual model. All the authors took part in designing the study. Data collection was undertaken by $\mathrm{KH}$ and $\mathrm{RB}$. Data analysis was undertaken by $\mathrm{KH}$, with contributions by DRJ and MJB. All the authors contributed to interpretation of the findings. The first draft was prepared by $\mathrm{RB}$ and all the authors took part in revision of the manuscript and approved the final version. $\mathrm{RB}$ and $\mathrm{KH}$ are guarantors of the paper.

Funding The study was funded by a grant from Leicester City Clinical Commissioning Group.

\section{Competing interests None declared}

Provenance and peer review Not commissioned; externally peer reviewed.

Data sharing statement Extra data can be accessed via the Dryad data repository at http://datadryad.org/ with the doi:10.5061/dryad.g2t66.

Open Access This is an Open Access article distributed in accordance with the Creative Commons Attribution Non Commercial (CC BY-NC 4.0) license, which permits others to distribute, remix, adapt, build upon this work noncommercially, and license their derivative works on different terms, provided the original work is properly cited and the use is non-commercial. See: http:// creativecommons.org/licenses/by-nc/4.0/

\section{REFERENCES}

1. Macinko J, Starfield B, Shi L. The contribution of primary care systems to health outcomes within Organization for Economic Cooperation and Development (OECD) countries, 1970-1998. Health Serv Res 2003;38:831-65.

2. NHS England. Five year forward view. London: NHS England, 2014

3. Starfield B, Shji L, Macinko J. Contribution of primary care to health systems and health. Milbank Q 2005;833:457-502.

4. Rasella D, Harhay MO, Pamponet ML, et al. Impact of primary health care on mortality from heart and cerebrovascular diseases in 
Brazil: a nationwide analysis of longitudinal data. BMJ 2014;349: g4014.

5. Shi L, Starfield B. The effect of primary care physician supply and income inequality on mortality among blacks and whites in US metropolitan areas. Am J Public Health 2001;91:1246-50.

6. Levene LS, Bankart J, Khunti K, et al. Association of primary care characteristics with variations in mortality rates in England: an observational study. PLoS ONE 2012;7: e47800.

7. Thorlby R. Reclaiming a population health perspective. Future challenges for primary care. London: The Nuffield Trust, 2013.

8. World Health Organization. World health report 2008. Primary health care. Now more than ever. WHO, 2008.

9. Baker $\mathrm{R}$, Jones $\mathrm{DR}$, Baker $\mathrm{R}$, et al. Monitoring mortality rates in general practice after Shipman. BMJ 2003;326:274-6.

10. Health and Social Care Information Centre. Indicator Portal. https:// indicators.ic.nhs.uk/webview/ (accessed 8 Apr 2015).

11. Health and Social Care Information Centre. Dataset: Estimates of Standardised Mortality Rates (SMR) <65 and 75: 2006-2010. https://indicators.ic.nhs.uk/download/GP\%20Practice\%20data/ Specification/SMR\%20v1.pdf (accessed 8 Apr 2015).

12. Wheller L, Baker A, Griffiths $C$. Trends in premature mortality in England and Wales, 1950-2004. Health Stat Q 2006;31:34-41.

13. Public Health England. Deaths from all causes under 75 years. http://www.apho.org.uk/resource/item.aspx?RID=97049 (accessed 8 Apr 2015).

14. Honeyford K, Baker R, Bankart MJG, et al. Estimating smoking prevalence in general practice using data from the Quality and Outcomes Framework (QOF). BMJ Open 2014;4:e005217.

15. Communities and Local Government. The English indices of deprivation 2010. London: Department for Communities and Local Government, 2011. ISBN: 978-1-4098-2924-9

16. Health and Social Care Information Centre. Estimates of Index of Multiple Deprivation (IMD) 2010 for GP practices. December 2011 https://indicators.ic.nhs.uk/webview/index/en/MyServer/ NHS-Information-Centre-indicators.c.MyServer/GP-Practice-data.d 48/Demography.d.77/Deprivation.d.202/Estimates-of-Index-ofMultiple-Deprivation-IMD-2010-for-GP-practices/fStudy/P01112 (accessed 9 Sep 2015).

17. Martin D, Wright JA. Disease prevalence in the English population: a comparison of primary care registers and prevalence models. Soc Sci Med 2009;68:266-74.

18. Barnett $\mathrm{K}$, Mercer SW, Norbury $\mathrm{M}$, et al. Epidemiology of multimorbidity and implications for health care, research, and medical education: a cross-sectional study. Lancet 2012;380:37-43.

19. GP Patient Survey. Surveys and reports. https://gp-patient.co.uk surveys-and-reports (accessed 8 Apr 2015).

20. Healthcare Commission. Practice ethnicity data for disease prevalence modeling. Eastern Region Public Health Observatory, 2010.

21. Health and Social Care Information Centre. Number of GPs per registered and weighted practice population. 2010. https://indicators. ic.nhs.uk/download/Infrastructure/Specification/GP\%20numbers\% 20v2.pdf (accessed 8 Apr 2015).

22. Gulliford MC, Jack RH, Adams G, et al. Availability and structure of primary medical care services and population health and health care indicators in England. BMC Health Serv Res 2004;4:12.

23. Szczepura A, Davies C, Fletcher J, et al. Efficiency and effectiveness in general practice. $J$ Manag Med 1993;7:36-47.

24. Gulliford M, Figueroa-Munoz J, Morgan M, et al. What does 'access to health care' mean?. J Health Serv Res Policy 2002;7:186-8.
25. Roland M, Elliott M, Lyratzopoulos G, et al. Reliability of patient responses in pay for performance schemes: analysis of national General Practitioner Patient Survey data in England. BMJ 2009;339: b3851.

26. Ashworth M, Schofield P, Doran T, et al. The Public Health Impact score: a new measure of public health effectiveness for general practices in England. Br J Gen Pract 2013;63:e291-9.

27. Honeyford K, Baker R, Bankart MJG, et al. Modelling factors in primary care quality improvement: a cross-sectional study of premature CHD mortality. BMJ Open 2013;3:e003391.

28. Calderón-Larrañaga $A$, Soljak $M$, Cecil $E$ et al. Does higher quality of primary healthcare reduce hospital admissions for diabetes complications? A national observational study. Diabet Med 2014;31:657-65.

29. Chatterjee G, Hadi AS. Regression analysis by example. 5th edn. Hoboken, NJ: John Wiley and Sons, 2012.

30. Sundquist J, Bajeka M, Jarman B, et al. Underprivileged area score, ethnicity, social factors and general mortality in district health authorities in England and Wales. Scand J Prim Health Care 1996;14:79-85.

31. Association of Public Health Observatories. Indications of Public Health in the English Regions. 4: Ethnicity and Health. http://www. apho.org.uk/resource/view.aspx?QN=IND SERIES (accessed 11 Nov 2015)

32. Fiscella K, Burstin HR, Nerenz DR. Quality measures and sociodemographic risk factors: to adjust or not to adjust. JAMA 2014;312:2615-16.

33. Shin DW, Cho J, Yang HK, et al. Impact of continuity of care on mortality and health care costs: a nationwide cohort study in Korea. Ann Fam Med 2014;12:534-41.

34. Levene SL, Baker R, Bankart MJ, et al. Association of features of primary care with coronary heart disease mortality. JAMA 2010;304:2028-34.

35. Kontopantelis E, Springate DA, Ashworth M, et al. Investigating the relationship between quality of primary care and premature mortality in England: a spatial whole-population study. BMJ 2015;350:h904.

36. Millett C, Car J, Eldred D, et al. Diabetes prevalence, process of care and outcomes in relation to practice size, caseload and deprivation: national cross-sectional study in primary care. $J R$ Soc Med 2007; 100:275-83

37. Doran T, Kontopantelis E, Valderas JM, et al. Effect of financial incentives on incentivised and non-incentivised clinical activities: longitudinal analysis of data from the UK Quality and Outcomes Framework. BMJ 2011;342:d3590.

38. Doran Tim, Kontopantelis Evangelos, Reeves David, et al. Setting performance targets in pay for performance programmes: what can we learn from QOF? 2014;348:g1595.

39. Bankart MJ, Anwar MS, Walker N, et al. Are there enough GPs in England to detect hypertension and maintain access? A cross-sectional study. Br J Gen Pract 2013;63:e339-44.

40. Thomson S, Osborn R, Squires D, et al. International profiles of health care systems. New York: The Commonwealth Fund, 2013

41. Marmot Review. Fair Society, Healthy Lives: Strategic Review of Health Inequalities in England Post 2010. London: Marmot Review; 2010.

42. Tarrant C, Angell E, Baker R, et al. Responsiveness of primary care services: development of a patient-report measure. Health Services and Delivery Research Programme. HMSO 2014. http://www.nets. nihr.ac.uk/_data/assets/pdf_file/0009/117378/FLS-09-1801-1029. pdf (accessed 24 Apr 2015). 